\title{
O horror como performance da morte: José Mojica Marins e a tradição do Grand Guignol
}

Lucio de Franciscis dos Reis Piedade

Laura Loguercio Cánepa

Resumo: $O$ artigo analisa aspectos da trilogia de Zé do Caixão, dirigida por José Mojica Marins (composta pelos filmes À meia-noite levarei sua alma, 1964; Esta noite encarnarei no teu cadáver, 1967; Encarnação do Demônio, 2008), sob a perspectiva da encenação do horror, originada na tradição do teatro francês do Grand Guignol (1897-1962). Discute-se, também, como os elementos gráficos do horror foram inseridos e reciclados nesses filmes, conforme mudanças de paradigmas do gênero no cenário internacional desde os anos 1960.

Palavras-chave: cinema brasileiro; cinema de horror; Grand Guignol; torture porn; José Mojica Marins.

Abstract: Horror as a performance of death: José Mojica Marins and the tradition of the Grand Guignol - This paper discusses aspects of the "Coffin Joe" trilogy directed by José Mojica Marins (At Midnight I'll Take Your Soul, 1964; This Night I'Il Possess Your Corpse, 1967; Embodiment of Evil, 2008), taking as its starting point the French tradition of the Theatre of the Grand Guignol (1897-1962). We also discuss how the graphic elements of horror were inserted and recycled in these films, according to paradigm shifts in the genre on the international scene since the 1960s.

Keywords: brazilian cinema; horror; Grand Guignol; torture porn; José Mojica Marins.

\section{Introdução: pensando o horror como espetáculo}

Entendido como produto de um gênero predominantemente narrativo, o horror artístico, quer se manifeste numa obra literária, teatral, pictórica ou audiovisual, é construído a partir de um dispositivo simbólico em que o espectador se vê diante de uma situação ficcional na qual os personagens estão ameaçadas por forças mortais cuja existência lhes é tão irresistível quanto incompreensível (BEGIN; GUIDO, 2010, p. 07). 
Desde o final dos anos 1970, esse gênero vem sendo alvo de atenção crescente dos estudos de cinema, em função de uma grande variedade de problemas teóricos que oferece à reflexão. Entre as abordagens teóricas do horror cinematográfico, pode-se destacar suas relações com as tradições literárias e religiosas, com os processos históricos e políticos, com as imagens de guerras, com as mudanças comportamentais, que se deram ao longo do século XX, com a evolução tecnológica, etc ${ }^{1}$

Mas o interesse teórico sobre o aspecto espetacular dos dispositivos do horror no cinema, muitas vezes originados em modelos teatrais, é mais recente. Tradições como a fantasmagoria do século XVIII e o melodrama cênico do século XIX, por exemplo, como mostram Bégin e Guido (2010, p. 8), chamam a atenção para uma especificidade do horror cinematográfico que é o efeito da confrontação imediata com a violência da experiência horrífica. Para Guido (2010, p. 15-16), diversos motivos e procedimentos do cinema de horror têm origem numa vasta cultura teatral, e a história desse gênero estaria emoldurada por uma referência reflexiva à mostração cênica (ibid.), conceito herdado de Gaudreault (1984) em suas reflexões sobre os regimes de representação originários do Primeiro Cinema (CANEPA; FERRARAZ, 2012, p. 9).

Não se trata, aqui, porém, de discutir filmes inspirados em peças teatrais, e viceversa. É sabido, por exemplo, que o filme que deu início ao primeiro ciclo do gênero em Hollywood, Drácula (Tod Browning, 1931), teve como inspiração a adaptação da Broadway de John Badelstorn, que estreara em 1927, e não a novela de Bram Stoker, publicada trinta anos antes da peça. Outro clássico influente, Os Inocentes (The Innocents, Jack Clayton, Inglaterra, 1961), adaptação da novela A volta do parafuso (1898), de Henry James, também fora inspirado no espetáculo The Innocents, dirigido pelo inglês William Archibald, em 1950, na Broadway.

O que se deseja discutir é outra questão: a relação dos filmes de horror com dispositivos exibicionistas de origem teatral. E, nesse sentido, sem dúvida o teatro de horrores francês do Grand Guignol se mostra como um dos pilares mais importantes para a constituição do horror cinematográfico desde o começo do século XX.

\section{O teatro de horrores e a tradição do Grand-Guignol}

Fundado, em 1897, pelo dramaturgo e encenador Oscar Méténier na antiga capela de um convento em Montmartre, o Théatre du Grand Guignol foi uma popular atração parisiense por mais de seis décadas, sobrevivendo quase ininterruptamente até 1962 . Nesse espaço dedicado aos horrores da carne e do espírito, foram encenados milhares de assassinatos, estupros, torturas sexuais, mutilações, aparições fantasmagóricas, surtos psicóticos, fantasias insanas, chacinas, cirurgias sem anestesia, transfusões de sangue,

1 Sobre isso, ver Canepa; Ferraraz (2012, p. 8). 
transplantes de órgãos e toda sorte de fatos chocantes, que atraíram noite após noite, para seus 293 lugares, uma plateia fiel, ávida por náuseas e sustos. ${ }^{2}$

Como descreve Biscaia Filho (2012, p. 15), Méténier tinha o hábito de preparar seu público desde o início do espetáculo, chegando ao teatro vestido de preto e cercado por dois guarda-costas, para, como um mestre de cerimônias vampiresco, narrar à plateia detalhes nauseantes sobre crimes bárbaros que ele supostamente acabara de ouvir na delegacia ambiente que, como lembram Hand e Wilson (2002, p. 268), ele conhecia bem, já que também trabalhara como secretário de Polícia. Depois disso, tinha início uma série de peças curtas, muitas vezes inspiradas nas manchetes que proliferavam nos tabloides da Europa, apresentadas em estilo derivado do naturalismo, que então dominava a cena teatral francesa.

O sucessor de Méténier, Max Maurey, chegado ao teatro em 1898, acrescentaria algumas novidades ao programa do Grand Guignol, especialmente uma dosagem calculada de humor, choque e drama, os quais garantiam ao espetáculo uma experiência emocional pretensamente próxima à de uma montanha-russa - tipo de diversão que também era moda nas cidades mais desenvolvidas do mundo naquela época.

Em 1903, ele chamaria à companhia o dramaturgo André de Lorde (1869-1942), que faria uma verdadeira transformação no modelo do Grand Guignol, ao dar início a adaptações de Edgar Allan Poe e de outros autores de ficção fantástica e de horror. Isso permitiu ao teatro reunir os usuais relatos chocantes às fantasias sobrenaturais - tendo sempre como atração principal a apresentação realista da violência através dos efeitos de maquiagem, mas carregada de sensacionalismo por meio do uso da luz, do som, das cores e da própria arquitetura soturna do teatro.

Como observa Biscaia Filho, com a chegada de De Lorde, "as possibilidades iam muito além dos fait divers e se estendiam para o verdadeiro horror." (BISCAIA FILHO, 2012, p. 17). É neste momento que o Grand Guignol consegue absorver todo um conjunto de narrativas horríficas antigas e modernas, proporcionando ao público um acúmulo de experiências cujo apelo se revelou irresistível.

Depois do final da Segunda Guerra, o teatro entrou em decadência, em parte por ter sido fechado apenas para soldados alemães durante a ocupação nazista, o que desmoralizou sua trupe diante dos concidadãos. Também os horrores vistos nos campos de batalha pareciam ter diminuído o potencial de choque dos espetáculos. Em 1947, cinquenta anos depois da fundação, a atriz inglesa Eva Berkson, que comprara o Grand Guignol, afirmaria: “cheguei à conclusão de que a única forma de assustar uma plateia francesa depois da Guerra é mutilar uma mulher em cena. Uma mulher de verdade, e jogar os pedaços ao público!" (ibid., p. 28).

2 Como exemplo das proezas do Grand Guignol, algumas informações sobre a maior estrela da companhia, Paula Maxa, não nos deixam mentir. "As estatísticas de sua carreira são um tanto peculiares. Segundo consta, foi assassinada mais de dez mil vezes, de sessenta formas diferentes; foi estuprada três mil vezes sob dúzias de circunstâncias; gritou 'socorro' 983 vezes, 'assassino', 1.263 vezes, 'estupro', 1.804,5 vezes" (BISCAIA FILHO, 2012, p. 22). 
Mas, como alegam Hand e Wilson (2002, p. 287), isso parece pouco convincente, já que a Primeira Guerra não tinha interrompido o sucesso do teatro, e a Segunda Guerra não impedira a evolução do gênero horror no cinema e nas histórias em quadrinhos, por exemplo. Mais provável, segundo os autores, é que o Grand Guignol não pudesse competir com o cinema, já que a audiência popular começava a satisfazer seu desejo de terror através de filmes de violência mais explícita, como os da companhia inglesa Hammer (de 1957 em diante) e os thrillers modernos, incluindo obras-primas como As diabólicas (Les Diaboliques, Henri-Georges Clouzot, 1954) e Psicose (Psycho, Alfred Hitchcock, 1960). Segundo os autores, "o cinema poderia oferecer todas as viagens impiedosas à monstruosidade humana, mas com todas as vantagens dos close-ups e da decupagem" (ibid.).

De fato, a fórmula do Grand Guignol não apenas tinha sido aprendida pelo cinema de horror ao longo daqueles anos, como seria implementada de maneira mais explícita justamente a partir do começo dos anos 1960, quando o teatro fechou suas portas. Para Hand e Wilson:

O Grand-Guignol é uma tradição teatral negligenciada que tem um impacto incalculável, mas tangível, em outros gêneros dramáticos e cinematográficos. (...) Absorveu os métodos de vanguarda do naturalismo, a simplicidade afiada do simbolismo, o clima e o estilo do expressionismo e até mesmo a violência subversiva do surrealismo. Em última análise, iria determinar a dramaturgia e o ritmo do drama de suspense subsequente, e também uma ampla gama de filmes dos gêneros terror e suspense. Isso sem falar na sua influência mais ampla cultura popular de ficção e quadrinhos para rádio e televisão. (lbid., p. 267; tradução dos autores)

\section{O Grand Guignol como modelo para o cinema}

O Grand Guignol inspirara imitadores, desde o começo do século XX, em cidades como Roma, Londres e Nova lorque, mas seria absorvido definitivamente pelo cinema a partir do começo dos anos 1960, após a decadência do sistema de estúdios de Hollywood, da flexibilização do código Hays (o código de autocensura que dominou Hollywood entre 1934 e meados dos anos 1960) e do surgimento de ciclos nacionais de horror em diferentes partes do mundo (como o Japão, o México e a Itália). Então, os cineastas passaram a testar os limites da censura e do público em filmes cada vez mais sangrentos, muitas vezes exibidos nos circuitos alternativos, que então se multiplicavam.

Exemplo pode ser encontrado em Os Olhos sem rosto (Les Yeaux Sans Visage, 1959), obra referencial do cineasta francês Georges Franju. Também conhecido como The horror chamber of Dr. Faustus, na versão (cortada) lançada nos EUA, o filme contava a história de um cirurgião que utilizava a pele das faces de jovens para restaurar a beleza de sua filha 
desfigurada, condenada a usar uma máscara de porcelana. Os olhos sem rosto continha uma das primeiras sequências explícitas de mutilação do cinema, quando o cirurgião desprega a pele do rosto de uma de suas vítimas.

Além de Franju, também merecem destaque, por incorporar em suas produções o espírito do Grand Guignol, o produtor David Friedman e o diretor Herschell Gordon Lewis, nos EUA. Notórios por prolífera parceria na linha de filmes conhecida como exploitation, eles foram responsáveis pela combinação de nudez com o sangue-e-tripas filmados a cores, notadamente na trilogia composta pelos filmes Banquete de sádicos (Blood Feast, 1963), Maníacos (2000 Maniacs!,1964) e Color me Blood Red (1965).

Vale, para explicitarmos a evocação desse espírito de violência explícita e episódica do Grand Guignol, uma rápida descrição da sequência inicial de Banquete de Sádicos, na qual uma jovem relaxa numa banheira cheia de espuma. O banho é interrompido por um estranho empunhando faca de açougueiro. Ele remove um dos olhos da jovem com a ponta da faca e, em seguida, desfere vários golpes até amputar a sua perna na altura do joelho. Após guardar cuidadosamente os pedaços removidos, sai de cena, deixando a vítima mutilada: um osso aparecendo entre as carnes sangrentas e dilaceradas do joelho, e a órbita ocular repleta de sangue.

Outros realizadores também foram longe ao explorar cenas aberrantes como as de Franju e Lewis. Um deles foi o japonês Nobuo Nakagawa, que, em 1961, filmou o sangrento pesadelo Jigoku, no qual dezenas de personagens são jogados num inferno onde sofrem as piores mutilações $E$, entre os que primeiro se aventuraram nas performances explícitas da morte, é fundamental destacar também um brasileiro: José Mojica Marins, que, em 1964, lançava À meia-noite levarei sua alma, primeiro filme de horror brasileiro a assumir-se como tal. Além de fenômeno de público, o filme transformaria seu realizador em figura midiática onipresente, e foi também o abre-alas de uma sequência de obras que marcariam momentos de extrema violência no horror cinematográfico brasileiro dos anos 1960.

\section{Mojica e o horror brasileiro}

Nos últimos anos, diferentes pesquisas acadêmicas e jornalísticas têm procurado tratar da presença do gênero horror no cinema brasileiro. ${ }^{3}$ Apesar de diferenças teóricas e metodológicas entre elas, pode-se apontar certa unanimidade em torno de alguns aspectos, tais como: a explosão do gênero ao longo dos anos 1970 através de dezenas filmes eróticos com elementos de horror (dentro de um ciclo mais amplo de cinema erótico conhecido como "pornochanchada"); a multiplicação de estilos e temas nos curtas-metragens na década de 1990 e no cinema digital nos anos 2000; a tendência do gênero a hibridações com outros, como a comédia, a pornografia e experiências mais anárquicas ou experimentais.

3 Entre elas, cabe destacar os trabalhos de Piedade (2012), Cánepa (2011), Souza (2011), etc, além de publicações em forma de artigos científicos, levantamentos jornalísticos e mostras de filmes como os trabalhos dos pesquisadores Primati (2013), Carreiro (2012), Barcinski e Finotti (1998), entre outros. 
Mas, sem dúvida, a maior unanimidade diz respeito à centralidade de figura de Mojica, diretor, produtor e ator também conhecido como Zé do Caixão. Um dos mais prolíficos realizadores do cinema de horror na América Latina (e ainda em atividade), ele realizou 24 longas-metragens e mais de duas dezenas de curtas desde 1953, além de incontáveis programas de rádio e de televisão, com participações também no teatro, na publicidade, nos parques de diversões e nas histórias em quadrinhos. Ademais do horror, Mojica transitou por outros gêneros, como o western, o melodrama e o sexo explícito - nos quais, como observa Carreiro (2012, p. 345), sempre manteve elementos oriundos da iconografia do horror.

Sua inserção no gênero se deu em 1964, quando lançou seu terceiro longa finalizado, À meia-noite levarei sua alma, dirigido, estrelado e escrito por ele a partir de um sonho em que alega ter sido levado à própria sepultura por um homem vestido de preto. Foi aí que teve início a trajetória cinematográfica do agente funerário Josefel Zanatas, o Zé do Caixão, sociopata blasfemo e poderoso que aterroriza uma cidadezinha do interior em sua busca da mulher que lhe dará o filho perfeito - na opinião dele, a única eternidade possível.

A saga de Zé, vingado por uma procissão de almas penadas que o leva à morte em um cemitério, cercado pelos cadáveres de suas vítimas, teria continuidade em 1967, quando foi realizado Esta noite encarnarei no teu cadáver, o maior sucesso da carreira de Mojica, no qual o personagem retorna, por um artifício de roteiro, na companhia de Bruno, seu assistente corcunda, que o auxiliará na violenta busca da mulher perfeita - que mais uma vez terminará na aniquilação do personagem, cercado pelos cadáveres de suas vítimas.

Apesar de o personagem permanecer na mídia nos anos seguintes, com aparições na TV, no rádio e nos quadrinhos, a história de Zanatas sofreria uma longa interrupção após o segundo filme, em função de mudanças de rumos e de contratempos na carreira de Mojica. Zé do Caixão também retornaria transfigurado em vários filmes posteriores do diretor, tanto na forma do mestre de cerimônias de $O$ estranho mundo de Zé do Caixão (1968) quanto no seu alter ego em fantasias metalinguísticas como O despertar da Besta (1970), Exorcismo negro (1974) e Delírios de um anormal (1978).

Mas Josefel Zanatas só viria a terminar seu périplo em 2008, no longa Encarnação do Demônio, depois de amargar quarenta anos de cadeia e de montar uma gangue de seguidores que finalmente lhe dá não apenas uma, mas sete mulheres dispostas a gerar sua prole. Esse filme, realizado por Mojica junto a uma equipe de jovens cineastas, veio na esteira do sucesso internacional conquistado por sua obra em coleções distribuídas em vídeo nos EUA e Europa nos anos 1990, e também na tendência contemporânea de filmes de horror explícitos apelidados de torture porn.

Neste artigo, focaremos nossa análise em alguns aspectos dos três filmes da saga de Josefel Zanatas (À meia-noite levarei sua alma, Esta noite encarnarei no teu cadáver e Encarnação do Demônio), deixando o restante da obra de Mojica para incursões posteriores. 


\section{Uma trilogia sangrenta}

A trilogia de Zé do Caixão teve, desde o início, características de violência explícita que fizeram a fama (e também parte da infâmia) angariada pelo diretor desde então, e que foi intensificada pelo desenvolvimento de seus famosos testes de atores, explorados pela imprensa sensacionalista ao longo dos anos. Nesses testes, atores amadores eram submetidos a diversas situações terríficas reais para mostrarem, supostamente, a coragem necessária para participar dos filmes de Mojica.

Mesmo antes de oficializar seus testes, porém, o primeiro filme da série já trazia sinais do que estava por vir. À meia-noite levarei sua alma tem sua estrutura dividida em uma sequência de episódios de cerca de dez minutos, cada uma delas encerrada por um assassinato ou momento de violência espetacular - tendo sempre Zé do Caixão como figura central, paramentado com seu figurino de capa e cartola, que destoa dos moradores da cidade e remete tanto à sua origem vagamente aristocrática quanto ao ambiente circense e de teatro popular.

Com isso, o filme produz um curioso amálgama de vários tipos de espetáculos e histórias de horror, reunindo blasfêmia (é inesquecível a cena em que Zé do Caixão assiste a uma procissão de Sexta-Feira Santa comendo um enorme pernil); ataques de animais peçonhentos (quando ele coloca uma aranha sobre o corpo amarrado de sua esposa); violência sexual (no estupro da noiva de seu melhor amigo, que a leva ao suicídio por enforcamento); cenas gráficas de violência (como o dedo decepado por Zé numa briga de bar e uma cabeça atravessada por uma coroa de espinhos); assombrações (quando a procissão dos mortos ataca Zé); cadáveres em decomposição (que ele encontra no cemitério, onde se refugia da perseguição dos mortos), etc.

Essas estratégias seriam intensificadas em Esta noite encarnarei no teu cadáver, quando ele e seu assistente abusarão de métodos violentos como sequestros, estupros, chantagens, assassinatos e múltiplas torturas (apelidadas de "testes do medo"), entre os quais a exposição de mulheres seminuas ao ataque de aranhas e cobras - com o detalhe de que os animais eram de verdade, o que intensificou enormemente a experiência das atrizes e do público.

Um aspecto que reforça o caráter espetacular e episódico dessas cenas é a autoconsciência a respeito de seu conteúdo violento e explícito. Sua encenação é sempre exibicionista, feita diante de plateias dentro do filme e endereçada de maneira claramente performática à plateia do cinema. E tais cenas têm seu impacto reforçado por fazerem uso de um tipo de realismo brutal, já que o cineasta constrói suas narrativas ficcionais submetendo seus atores a situações reais de violência originadas desde seus testes de atores, o que garante atuações autênticas de intérpretes inexperientes.

Mas isso não é tudo. Nesse filme, as visões místicas e infernais que encerravam o episódio anterior com a procissão de mortos ganha características mais espetaculares. Na metade do filme, Zé do Caixão é violentamente retirado da cama por um espectro e arrastado até um cemitério. Lá, aterrorizado, vaga pelo terreno acidentado e 
pelas sepulturas, de onde os mortos o assombram com seus gemidos e tentam se erguer para agarrá-lo. No auge do pavor, mãos descarnadas saídas de um túmulo o seguram fortemente e ele é tragado para dentro da terra. Então, Zé do Caixão percebe, em seu terror, estar nas profundezas do inferno, que agora se apresenta em cores vivas, e não mais no preto e branco em que seus filmes mergulhavam até então. Percorrendo como um Dante mambembe seus corredores e labirintos, Zé presencia as torturas infligidas pelos demônios aos pecadores.

Segundo o folclorista Luís da Câmara Cascudo, na visão popular brasileira, a concepção de inferno é cristã, "com as transformações, convergências e adaptações da mentalidade local" (1993, p. 451), o que se conforma nas imagens trazidas pelo colono português, com suas "grelhas ardentes, caldeiras borbulhantes, chumbo derretido, banhos de fogo, espetos, garfos, espontões, espadas vermelhas, instrumentos de suplício singulares para esses incorpóreos" (ibid.). De acordo com essa concepção, herdada da Antiguidade, também se estabelece geograficamente no mundo subterrâneo a morada dos mortos, posteriormente local de punição e mal eterno, para onde são arrastadas as almas humanas que se desviavam do caminho da retidão.

É esse o universo que traga Zé do Caixão, mas se observa que o inferno de Mojica é circense, assemelhando-se a uma incursão à casa dos horrores de um parque de diversões. Cenograficamente elaborado com poucos recursos que envolvem cartolina, papel celofane, gesso e até pipoca, o filme também revela, como mostram Barcinski e Finotti (1998, p. 151), o talento visionário de Mojica, "sem dúvida uma das sequências mais inventivas da história do cinema brasileiro e digna de figurar em qualquer antologia das melhores cenas do cinema de horror". A representação desse inferno remete à visão popular trazida pelos cristãos europeus (vale lembrar que Mojica é descendente de espanhóis) e marcante na iconografia deixada por pintores desde a Idade Média, como Giotto (1266 - 1337), Bosch (1450 - 1516) e mais tarde Goya (1746 - 1828); e na literatura, notadamente no Dante Alighieri (1265 - 1321) de A Divina Comédia. Este último, aliás, tem sua obra relida, de certa forma, no filme de Mojica, conforme Fernandez relata em suas observações sobre o Esta noite encarnarei no teu cadáver:

As correspondências entre A Divina Comédia e o filme são numerosas. A descida aos infernos de Zé começa quando ele cai sobre a lama onde estão deitados os danados (canto VI do Inferno). Em seguida, há um terremoto (canto III), que leva Zé ao círculo seguinte; os demônios chicoteiam (canto XVIII) e cravam tridentes na carne dos pecadores (canto XXII); estes se arrastam pelos caminhos (canto XXIX); sofrem crucificações (cantos XVI e XXIII); são presos com correntes (canto XXXI); mordidos por serpentes (canto XXIV); enterrados de ponta cabeça no fundo da gruta (canto XIX) e colocados em poços (canto XXXI). (FERNANDEZ, 2007, p. 44) 
Mojica aproveita, portanto, para mostrar pela primeira vez no cinema brasileiro, nas perambulações de seu personagem por esse inferno colorido de isopor e cartolina, corpos nus sendo torturados, com especial destaque para as mulheres, numa exibição de corporalidade grotesca comum nas obras dos artistas que retratavam cenas apropriadamente denominadas "dantescas" referentes ao inferno e juízo final.

Cenas semelhantes aparecem em Encarnação do Demônio, que tem nova incursão de Zé do Caixão no reino dos mortos, dessa vez ao Purgatório. Ciceroneado pelo Mistificador (José Celso Martinez Corrêa), Zé presencia, em uma montanha de círculos ascendentes, representando os pecados capitais (novamente, portanto, tendo A Divina Comédia como fonte de inspiração), a flagelação das almas, que se contorcem em espetáculo de gozo e dor, excitando-se sexualmente enquanto têm suas vísceras arrancadas, canibalizadas e cruelmente brutalizadas.

Isso se complementa numa visão particular do inferno na masmorra que Zé do Caixão mantém em seu covil, versão mais explícita e violenta do cativeiro em que detinha suas vítimas em Esta noite encarnarei no teu cadáver. Aqui, ele se apropria da estética do torture porn, subgênero do horror assim rotulado para denominar filmes que têm como ponto central a tortura explícita e seus detalhes sangrentos, e que se popularizou em séries como Jogos Mortais (Saw, 2004) e O Albergue (Hostel, 2005).

Nessas produções, a tortura é a fonte primeira do horror e não uma contingência da trama. E, no caso de Encarnação do Demônio, ainda que se encaixem na narrativa, as sequências em que personagens são torturados e seviciados também funcionam como blocos independentes, que poderiam ser montados separados ou colados a outros de forma a construir um compêndio de perversões que poderiam ou não ser unidos por algum eixo dramático.
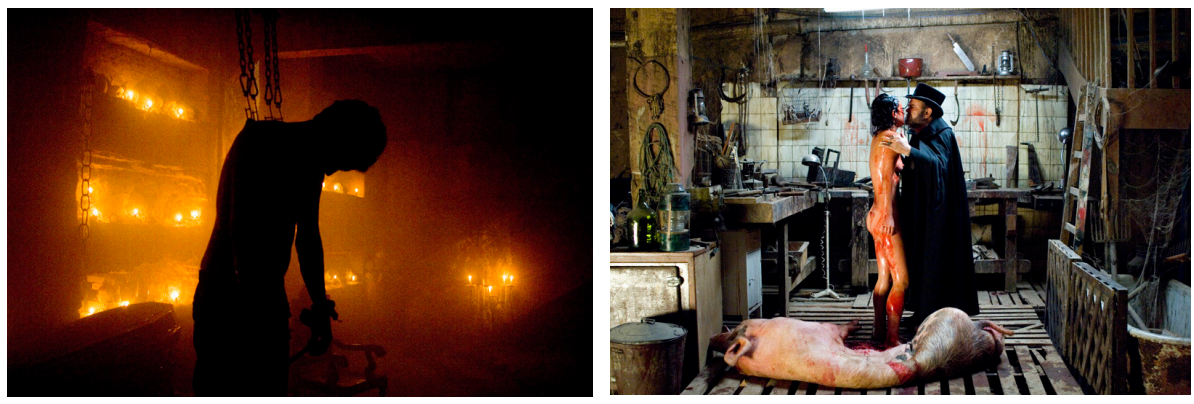

Figs. 1 e 2. Reprodução de fotogramas de Encarnação do Demônio.

Fonte: Disponível em: http://www.encarnacaododemonio.com.br/sala-de-imprensa. Acessado em 01/12/2013.

Tais sequências justificam essa aproximação com o torture porn ou torture horror, pois, como sugere Morris (2010, p. 43-44), o objetivo comum nos filmes de horror é o desenvolvimento de um enredo assustador que será apreciado pelo medo que proporciona, enquanto a meta do torture horror é um enredo com representações 
de torturas, sendo importante que os personagens - torturadores e torturados - se comportem na narrativa como fonte primária de pavor, daí uma clara aproximação com o modelo do Grand Guignol. As descrições infernais de Encarnação do Demônio funcionam como um quadro vivo no qual os inimigos capturados por Zé do Caixão são submetidos aos mais bárbaros suplícios, presos em sua câmara de horrores cenograficamente elaborada. Mas não só eles: as aspirantes à posição de "mulher perfeita", submetidas a um processo de seleção doentio (que é o mote do personagem desde o primeiro filme), são também expostas a variados suplícios.

Exemplos de torture horror podem ser encontrados em vários momentos. Os inimigos policiais, dois homens e duas mulheres, são emboscados enquanto espancam o corcunda Bruno. Um dos homens é crucificado, tendo os braços abertos sobre coluna de madeira. Suas mãos são também amarradas, pregadas a marteladas, em mais uma demonstração da relação da obra de Mojica com as imagens religiosas. O outro policial (interpretado pelo performer Freak Garcia) tem a pele das costas trespassada por ganchos (Figura 1), pelos quais é pendurado, de acordo com a prática conhecida como suspensão corporal.

O destino das policiais femininas não é mais ameno. Após serem chicoteadas por Zé do Caixão, uma é afogada em um balde cheio de baratas, enquanto sua colega acaba com um rato vivo inserido na vagina. Também a advogada aprisionada com os militares é escalpelada, tendo o couro cabeludo cortado na nuca, e a pele puxada sobre sua cabeça.

Mas, sobretudo, as candidatas a "noivas do monstro", retomando as práticas de Zé do Caixão em Esta noite encarnarei no teu cadáver, são testadas naquele local de martírios, um misto de sala de torturas com centro cirúrgico, decorado com instrumentos cortantes e perfurantes. Uma delas, nua sobre uma maca, tem uma seringa com longa agulha introduzida em detalhe na nádega. Logo em seguida, em close-up, Zé do Caixão tira fatia do traseiro da mulher. As provas a que são submetidas as outras cativas vão de mergulhos em tonéis de vísceras, ferros em brasa, peles arrancadas, com destaque para a sequência em que a uma jovem é retirada de dentro da carcaça de um porco, onde estava confinada (Figura 2).

Mas, se podemos fazer uma analogia com o inferno e os tormentos dos condenados, representados na iconografia cristã, também podemos relacionar os servos de Zé do Caixão - dois casais com traços e figurinos que podem ser associados a influentes produções de horror - aos demônios responsáveis pelos martírios infernais e por suas atualizações no cinema de horror dos últimos cinquenta anos.

O personagem de Rubens Mello - eleito sucessor de Zé do Caixão em concurso patrocinado pela revista Trip e pelo extinto jornal Notícias Populares -, de barba negra cerrada, não deixa dúvidas sobre sua semelhança com o jovem Mojica, a quem rende tributo. O tatuador Zumba, com seu porte avantajado, tatuagens e perfurações - nota-se a escalação no elenco de profissionais da body modification que dão um tom mais verossímil para as cenas de flagelações - veste um avental sujo que lembra o assassino Leatherface de O Massacre da Serra Elétrica (The Texas Chainsaw Massacre, Tobe Hooper, EUA, 1974). 
Também encontramos traços dos cenobitas derivados da subcultura fetichista - conforme sugere Schrek (2000, p. 211), de Hellraiser, Renascido do Inferno (Hellraiser, Clive Barker, 1987) - nas duas servas (Karina Bez Batti e Fernanda Brandão), em suas indumentárias de couro, sobrancelhas raspadas e correntes, assemelhando-se a dominatrixes saídas das profundezas. Coadjuvantes e algumas vezes responsáveis pelos suplícios, elas conformam nessa ambiência infernal a essência do torture porn, ou seja, o horror da morte violenta elevado à categoria de produto estético ou forma plástica.

Em Encarnação do Demônio, então, essa tendência contemporânea ao horror explícito é resolvida como resultado da soma do pioneirismo de Mojica no filão, desde os anos 1960, à participação de colaboradores jovens que dominam esse novo referencial, como o roteirista e assistente de direção Dennison Ramalho e o técnico em efeitos especiais Kapel Furman. Com uma equipe mais numerosa e orçamento proporcionalmente muito maior que o das produções anteriores, Mojica foi capaz de realizar um autêntico filme de Zé do Caixão e, ao mesmo tempo, alinhar-se ao cinema de horror mais extremo da atualidade.

\section{Conclusão: horror performático como tradição nacional}

As sequências descritas se enquadram no questionamento de Schneider (2001, p. 71) sobre como os assassinatos cometidos pelos monstros cinematográficos (no caso a categoria de "monstro moral" à qual o coveiro originalmente pertence $)^{4}$ podem ser compreendidos em sua forma artística. Segundo o autor, uma seletiva pesquisa do gênero indica duas tendências principais na representação artística do assassinato: de um lado, filmes de horror em que as mortes são produtos artísticos; de outro, filmes em que elas são performances artísticas. A primeira tendência estaria centralizada, sob um ponto de vista estético, na cena do crime e nos restos mortais, a despeito do modus operandi ou presença do assassino; a segunda teria como foco a maneira como o assassino comete os crimes, ou seja, à sua encenação.

É evidente que tais tendências se entrecruzam, mas as ações de Zé do Caixão parecem nitidamente ancoradas na segunda, principalmente em Encarnação do Demônio, filme no qual reverberam, além do repertório de Mojica dos anos 1960, também ecos de produções dos anos 1970 como O Abominável Dr. Phibes (The Abominable Dr. Phibes, Robert Fuest, Reino Unido/EUA, 1971) e As Sete Máscaras da Morte (Theater of Blood, Douglas Hickox, Reino Unido, 1973), e slashers ${ }^{5}$ dos anos 1980 como a série Sexta Feira 13, nas quais as vítimas são mortas sequencialmente de modos diversificados, de tal forma que cada morte supere a anterior em invencionice e sanguinolência.

4 Utilizamos o conceito de monstro moral teorizado por Martín (2002, p. 150): indivíduo antissocial que traz o caos para a sociedade em que vive. Em sua psicopatia é incapaz de sentir simpatia por outras pessoas e de distinguir entre o bem e o mal, não colocando barreiras às suas inclinações criminosas.

5 Filmes de "contagem de cadáveres" protagonizados por psicopatas geralmente mascarados. 
Numa cultura como a brasileira, na qual as narrativas violentas proliferam tanto na ficção quanto no jornalismo, e na qual o cinema de horror tem sido um gênero muito popular desde pelo menos a metade do século XX, não há motivos para se estranhar o pioneirismo, a longevidade e a influência da obra de José Mojica Marins. Na concepção de mundo vista pela loucura de Zé do Caixão, ele é o ator principal de um circo de horrores no qual se efetua o distanciamento do mundo ordinário.

Sua influencia é notória tanto em filmes eróticos brasileiros de horror do começo dos anos 1980, como O Pasteleiro (David Cardoso, episódio de Aqui tarados!, 1980) e O Castelo das Taras (Julius Belvedere, 1982), quanto em experiências de gore e horror explícito contemporâneas, como as dos curtas-metragens de Dennison Ramalho Amor só de mãe (2003) e Ninjas (2010), aclamados mundialmente, e dos longas digitais de Rodrigo Aragão (Mangue Negro, 2009; A noite do Chupa-Cabras, 2011; Mar negro, 2013) e Paulo Biscaia Filho (Morge story, 2009; Nervo craniano zero, 2011) que também têm encontrado franca circulação em festivais dentro e fora do Brasil, entre dezenas de outras obras que se poderia citar.

Ao desenvolver essa tradição nacional ainda pouco observada no âmbito dos estudos acadêmicos de cinema e audiovisual, percebe-se que Mojica foi capaz de inserir o cinema brasileiro numa tendência que, ao longo de mais de cem anos em cartaz nos palcos e nas telas, vem buscando confrontar os espectadores com a experiência da morte violenta, numa constante invenção de novas formas de representar o horror e o caos da existência humana.

Lucio de Franciscis dos Reis Piedade é doutor em Multimeios pela Unicamp e pós-doutorando bolsista Fapesp junto ao Programa de Pós-Graduação em Comunicação da Universidade Anhembi Morumbi.

reis.lucio@gmail.com

Laura Loguercio Canepa é doutora em Multimeios pela Unicamp e docente do Programa de Pós-Graduação em Comunicação da Universidade Anhembi Morumbi.

laura_canepa@yahoo.com.br

\section{Referências}

BARCINSKI, A.; FINOTTI, I. Maldito - A vida e o cinema de José Mojica Marins, o Zé do Caixão. São Paulo: Editora 34, 1998.

BÉGIN, R.; GUIDO, L. Présentation. Revue d’etudes cinematographiques, Qébec, Université de Montreal, v. 20, n. 2-3, 2010, p. 7-11.

BISCAIA FILHO, P. Palcos de Sangue. Belo Horizonte: Estronho, 2012. 
CAMARA CASCUDO, L. Dicionário do folclore brasileiro. Belo Horizonte: Itatiaia, 1993.

CÁNEPA, L. À meia-noite levarei sua alma. In: ALMEIDA, R.; FERREIRA-SANTOS, M. O cinema como itinerário de formação. São Paulo: Képos, 2011, p. 35-56.

; FERRARAZ, R. Espetáculos do medo: o horror como atração no cinema japonês. Revista Contracampo, Niterói, Contracampo, n. 25, p. 4-23, dez., 2012.

CARREIRO, R. El problema del estilo em Jose Mojica Marins. In: DÍAZ-ZAMBRANA, R.; TOMÉ, P. (eds). Horrofílmico: Aproximaciones al cine de terror em Latinoamérica y el Caribe. San Juán: Isla Negra Editores, 2012, p. 342-358.

FERNANDEZ, A. A. Um arranjo prosaico e extravagante. In: PUPPO, E. (ed.). José Mojica Marins: 50 anos de cinema. São Paulo: Heco produções/CCBB, 2007, p. 41-48.

HAND, R.; WILSON, M. Grand-Guignol: The French Theatre of Horror. London: University of Exeter Press, 2002.

GAUDREAULT, A. Narration and monstration in the cinema. In: Journal of Film and Video, Vol. 39, n. 02. University of Ilinois Press, Spring, 1987, p. 29-41.

GUIDO, L. De l'opéra de l'oeil aux films à sensation: musique et théâtralité aux sources de l'horreur cinématographique. Revue d’etudes cinematographiques, Qébec, Université de Montreal, v. 20, n. 2-3, p. 13-40, 2010.

LINK, L. O Diabo: mascara sem rosto. São Paulo: Companhia das Letras, 1998.

MARTÍN, S. Monstruos al final del milenio. Madrid: Imágica Ediciones, 2002.

MORRIS, J. The Justification of Torture-Horror. In: FAHY, T. (ed.). The Philosophy of Horror. Lexington, Kentucky: University Press of Kentucky, 2010, p. 42-55.

PIEDADE, L. F. dos R. As belas e a Fera: monstruosidade e universo feminino no estranho mundo de José Mojica Marins. In: GRUPO DE TRABALHO IMAGEM E IMAGINÁRIOS MIDIÁTICOS, Juiz de Fora. Anais... Juiz de Fora, 2012.

PRIMATI, C. Sangue, sexo e riso: Espectros do horror no cinema brasileiro. In: PUPPO, E. (ed). Horror no cinema brasileiro. Disponível em: <http://www.portalbrasileirodecinema.com.br/horror/ensaiosangue-sexo-riso-por-carlos-primati.php?indice=ensaios>. Acesso em: 12 ago. 2013.

PUPPO, E. (ed.). José Mojica Marins: 50 anos de cinema. São Paulo: Heco produções/CCBB, 2007.

SENADOR, D. P. Das primeiras experiências ao fenômeno Zé do Caixão: Um estudo sobre o modo de produção e a recepção dos filmes de José Mojica Marins entre 1953 e 1957. Dissertação (Mestrado em Ciências da Comunicação) - Universidade de São Paulo, São Paulo, 2008.

SOUZA, C. C. Estes praticamente estranhos filmes de horror nacional. Canibuk, 6 nov 2011. Disponivel em: <http://canibuk.wordpress.com/2011/11/06/estes-praticamente-estranhos-filmes-de-horrornacional/>. Acesso em: 8 jan. 2013.

SCHNEIDER, S. J. Murder as Art/The Art of Murder: aestheticising violence in modern cinematic horror. In: BLACK, A. (ed.). Necronomicon: the journal of horror and erotic cinema. Hereford: Noir Publishing, 2001, 4 vol, p. 65-85.

SCHREK, N. The Satanic Screen: an illustrated guide to the devil in the cinema. London: Creation Books, 2000. 